Journal of Clinical Investigation

Vol. $43, \mathrm{No} .5,1964$

\title{
The Effects of Noncalorigenic Congeners of Salicylate on the Peripheral Metabolism of Thyroxine*
}

\author{
Kenneth A. Woeber and Sidney H. Ingbar \\ (From the Thorndike Memorial Laboratory and Second and Fourth [Harvard] Medical Serv- \\ ices, Boston City Hospital, and the Department of Medicine, Harvard \\ Medical School, Boston, Mass.)
}

Various experiments have indicated the presence in whole human serum of three major thyroxine $\left(\mathrm{T}_{4}\right)$-binding ${ }^{1}$ proteins : $\mathrm{T}_{\mathbf{4}}$-binding globulin ( $T B G), T_{4}$-binding prealbumin (TBPA), and albumin $(1,2)$. It is well established that, in vitro, TBG and TBPA are the major $\mathrm{T}_{4}$-binding proteins, whereas albumin is a relatively weak secondary carrier (3-5). These proteins interact with the hormone in a reversible binding equilibrium in which the majority of the hormone is bound but a measurable proportion is unbound or free. Free $\mathrm{T}_{4}$ has been suggested as the metabolically active component available to the cells in vivo for degradation, excretion, and initiation of hormonal action, with the bound hormone acting as a metabolically inert reservoir (3-5).

The role of TBG in the transport and peripheral metabolism of $\mathrm{T}_{4}$ in man is well accepted. This acceptance is based on studies demonstrating a consistent relationship between changes in the $\mathrm{T}_{4}$-binding activity of TBG, as assessed by electrophoresis in vitro and changes in the concentration and fractional turnover of $\mathrm{T}_{4}$ in vivo (6-8). From these observations, the conclusion has been drawn that TBG regulates the peripheral metabolism of $T_{4}$ by limiting the concentration of unbound hormone.

The existence of TBPA as a normal constituent of human serum has been satisfactorily demonstrated by, several techniques, and earlier doubts concerning its function in binding $\mathrm{T}_{4}$ at physiological $\mathrm{pH}$ have been dispelled $(5,9,10)$. The role, if any, of TBPA in regulating the peripheral metabolism of $\mathrm{T}_{4}$ in vivo has remained uncertain.

* Submitted for publication December 9, 1963 ; accepted January 8, 1964.

Supported in part by research grant Am-00267-10 from the National Institute of Arthritis and Metabolic Diseases, Bethesda, Md.

${ }^{1} \mathrm{~T}_{4}$ refers to the levorotatory isomer of thyroxine.
As in the case of TBG, attempts have been made to correlate changes in the $\mathrm{T}_{\mathbf{4}}$-binding activity of TBPA in vitro with changes in the volume of distribution and fractional turnover of hormone in vivo. Thus, certain abnormal states, such as fever and malignancy, have been found accompanied by a decrease in $\mathrm{T}_{4}$ binding by TBPA (4, $10,11)$ and an increase in the fractional rate of turnover of $T_{4}(12,13)$. Since these states are usually associated with hypermetabolism, and since in the absence of known alterations of $T_{4}$ binding, hypermetabolism per se may be accompanied by an increase in the fractional turnover of hormone $(12,14)$, changes in $T_{4}$-metabolism in these states cannot be ascribed to changes in hormonal binding. Similarly, salicylate and 2,4dinitrophenol have been shown to decrease $\mathrm{T}_{4}$ binding by TBPA in vitro $(5,15,16)$ and to accelerate the fractional turnover of $\mathrm{T}_{4}$ in man $(17,18)$, but since both agents uncouple oxidative phosphorylation and induce a severe hypermetabolism $(19,20)$, again the changes in $\mathrm{T}_{4}$ metabolism that these agents induce cannot necessarily be ascribed to an inhibition of $\mathrm{T}_{4}$-binding by TBPA.

Previous reports have indicated that certain congeners of salicylate do not uncouple oxidative phosphorylations in vitro (19) or stimulate oxygen consumption in vivo $(21,22)$. We therefore made a search among these compounds for inhibitors of $T_{4}$ binding by TBPA in order to study their effects on $\mathrm{T}_{4}$-metabolism in man.

\section{Methods and Materials}

In vitro studies

The effect of benzoic acid and a number of its hydroxy-, dihydroxy-, and amino-substituted derivatives ${ }^{2}$ on the binding of $T_{4}$ in normal serum was assessed by electrophoretic and dialysis techniques.

${ }^{2}$ Obtained from $\mathrm{K} \& \mathrm{~K}$ Laboratories, Jamaica, N. Y. 
Assessment of $T_{4}$ binding by filter paper clectrophoresis. By methods described in detail elsewhere (8), electrophoretic studies of the binding of $T_{4}$ were carried out in fresh serum from two normal donors. Samples of serum were enriched with a tracer amount of $\mathrm{I}^{131}$-labeled $\mathrm{T}_{4}{ }^{3}(2 \mu \mathrm{c}$ per $\mathrm{ml}$, approximately $4 \mu \mathrm{g}$ per $100 \mathrm{ml}$ ) and varying quantities of stable $T_{4}$, sufficient to permit estimation of the $\mathrm{T}_{4}$-binding capacities of TBG and TBPA. Inhibitory effects of benzoic acid derivatives were tested in two ways. First, serum was enriched with derivatives to the desired molarity by adding to nine parts of serum one part of the derivative dissolved in isotonic saline solution; control sera were comparably diluted with saline alone. Second, derivatives were tested for inhibitory potency by adding them directly to the buffer in which electrophoresis was performed. The $\mathrm{pH}$ of the buffer was readjusted when necessary.

Electrophoresis of serum specimens was performed on Whatman 3 filter paper in Tris-maleate buffer, $\mathrm{pH} 8.6$ (8). In experiments with derivatives added directly to serum, control and experimental samples were subjected to electrophoresis on the same filter paper sheet. In experiments in which buffer media were enriched with derivatives, duplicate samples of labeled serum were concurrently subjected to electrophoresis in unenriched buffer. Electrophoresis was allowed to proceed for 15 hours at $120 \mathrm{v}$. Assessment of the distribution of labeled $\mathrm{T}_{4}$ among TBG, TBPA, and albumin and calculation of the $T_{4}$-binding capacities of $T B G$ and TBPA were carried out by methods described in detail elsewhere (8). All experiments were performed at least twice and usually more often; results obtained with each derivative in separate experiments agreed closely.

Assessment of $T_{4}$ binding by agar gel electrophoresis. Studies were conducted on glass slides in an agar gel 4 (100 mg agar per $100 \mathrm{ml}$ ) prepared in $0.10 \mathrm{M}$ phosphate buffer, $\mathrm{pH}$ 7.4.5 Sera were enriched only with tracer quantities of $\mathrm{I}^{131}$-labeled $\mathrm{T}_{4}$. Samples of normal serum were diluted $(9: 1)$ with benzoic acid derivatives dissolved in isotonic saline solution. Control specimens were comparably diluted with saline alone. Electrophoresis was allowed to proceed for 3 hours at a current of $10 \mathrm{ma}$. Specimens were then dried under an infrared lamp, and radioautographs were prepared according to methods described previously (5). Thereafter, with the aid of the radioautographs, the zones containing TBG, albumin, and TBPA were sectioned, removed from the slide, and counted directly in a well-type scintillation counter.

Assessment of $T_{4}$ binding by dialysis techniques. The effect of benzoic acid derivatives on the rate of dialysis of $\mathrm{T}_{4}$ from normal human serum was determined by methods, detailed elsewhere (5), for assessing the effects of salicylate itself.

In vitro studies of thyroxine degradation. Slices of kidney cortex were obtained from freshly killed Sprague-

3 Obtained from Abbott Laboratories, Oak Ridge, Tenn. 4 Difco Laboratories, Detroit, Mich.

5 The authors are grateful to Dr. Frederick S. Bigelow for assistance in performing this technique.
Dawley rats. Approximately $100 \mathrm{mg}$ of tissue was placed in Erlenmeyer flasks containing $2.0 \mathrm{ml}$ of Krebs-Ringer phosphate buffer, $\mathrm{pH} 7.4$, enriched with either labeled $\mathrm{T}_{4}$ alone $(4 \mu \mathrm{c}$ per $\mathrm{ml}$, approximately $8 \mu \mathrm{g}$ per $100 \mathrm{ml}$ ) or labeled $\mathrm{T}_{4}$ and benzoic acid derivative. Slices from each rat were apportioned into duplicate control and experimental vessels. These, together with vessels containing no slices and serving as tissue-free controls, were then incubated under $100 \%$ oxygen at $37^{\circ} \mathrm{C}$ for 3 hours. Thereafter, $1 \mathrm{ml}$ of human serum was added to the incubation mixture to stop further hormonal degradation and to prevent the subsequent artifactual appearance of iodide during chromatography (23). Tissues were then homogenized in their own serum-enriched incubation media, and samples of the homogenate were subjected to ascending filter paper chromatography in a butanol-dioxane-2 $\mathrm{N}$ ammonia $(4: 1: 5)$ solvent system. Localization of the substrate $T_{4}$ and the products of hormonal degradation and determination of their relative proportions were carried out with an automatic strip scanner and electronic integrator by methods described previously (24). Values for the percentile degradation of $T_{4}$ were corrected for the non- $T_{4}$ radioactivity present in the tissue-free control samples.

\section{In vivo studies}

Studies of thyroxine turnover in vivo. Studies of the turnover and degradation of $\mathrm{I}^{131}$-labeled $\mathrm{T}_{4}$ were carried out in eight patients: four of the patients had no endocrine or systemic disease; three had primary myxedema, one (A.S.) receiving treatment with $3 \mathrm{~g}$ of desiccated thyroid daily, and the other two (M.F. and B.P.) being untreated. The eighth patient, who had hypopituitarism, was studied twice before and once during replacement therapy with cortisone. In vivo metabolism of $\mathrm{T}_{4}$ was assessed by methods detailed elsewhere (25). Briefly, each patient was given a single iv injection of $50 \mu \mathrm{c}$ (approximately $1.5 \mu \mathrm{g}$ ) of $\mathrm{I}^{131}$-labeled $\mathrm{T}_{4}$ dissolved in $1 \%$ human serum albumin. In patients with normal thyroid function, thyroidal recycling of inorganic $\mathrm{I}^{131}$ liberated by the peripheral degradation of labeled hormone was prevented by the administration of $30 \mathrm{mg}$ of methimazole every 6 hours. After injection of the labeled hormone, daily blood samples and, in patients R.G. and B.P., 24hour urine collections were obtained for a total of from 14 to 21 days. After an initial control period of 6 to 8 days, gentisic acid, gamma-resorcylic acid, or, in the case of M.M., salicylamide was given in gelatin capsules in divided daily doses of from 4 to $12 \mathrm{~g}$. The derivative was continued for from 6 to 9 days. In most instances, samples of blood were obtained for several days after the derivative had been discontinued. In two patients, A.S. and B.P., para-hydroxybenzoic acid was begun when gamma-resorcylic acid was stopped, and collection of blood samples was continued for an additional 6 to 7 days.

The fractional rate of hormonal turnover (k) during the control and experimental periods was determined from the declining concentration of the radioactivity in 
serum by the method of least squares. Data obtained during the first 24 to 48 hours of the control and experimental periods, however, were omitted from this calculation to permit the initial equilibration or re-equilibration, respectively, of the injected labeled material. Values for the $T_{4}$ distribution space (TDS) during the initial control period were calculated as the quotient of the injected radioactivity and the zero-time value of the radioactivity in serum obtained by extrapolating the calculated regression equation. The TDS during the administration of the benzoic acid derivatives, however, could not be calculated by this method. Accordingly, the percentage of the injected radioactivity remaining in the body at the beginning of the experimental period was calculated from the control fractional turnover rate. The TDS during the experimental period could then be calculated as the quotient of this quantity and the simultaneous concentration of the radioactivity in serum ob- tained from the calculated regression equation for the experimental period.

The daily clearance of $T_{4}$ and the daily rate of disposal of hormonal iodine were calculated for each period from the calculated values for $k$ and TDS and the concentration of hormonal iodine in the serum (4). In two patients, R.G. and B.P., the clearance of $T_{4}$ by degradative, rather than excretory, processes was calculated before, during, and after administration of the benzoic acid derivative (8). This "degradative clearance" was calculated from the daily 24-hour urinary excretion of $\mathrm{I}^{131}$ and the mean concentration of the radioactivity in serum during that same 24-hour period.

Either serum protein-bound iodine $(\mathrm{PBI})$ or butanolextractable iodine $(\mathrm{BEI})^{6}$ along with basal oxygen con-

6 Analyses for PBI and BEI were performed in the Boston Medical Laboratory by a modification of the method of Zak (26).

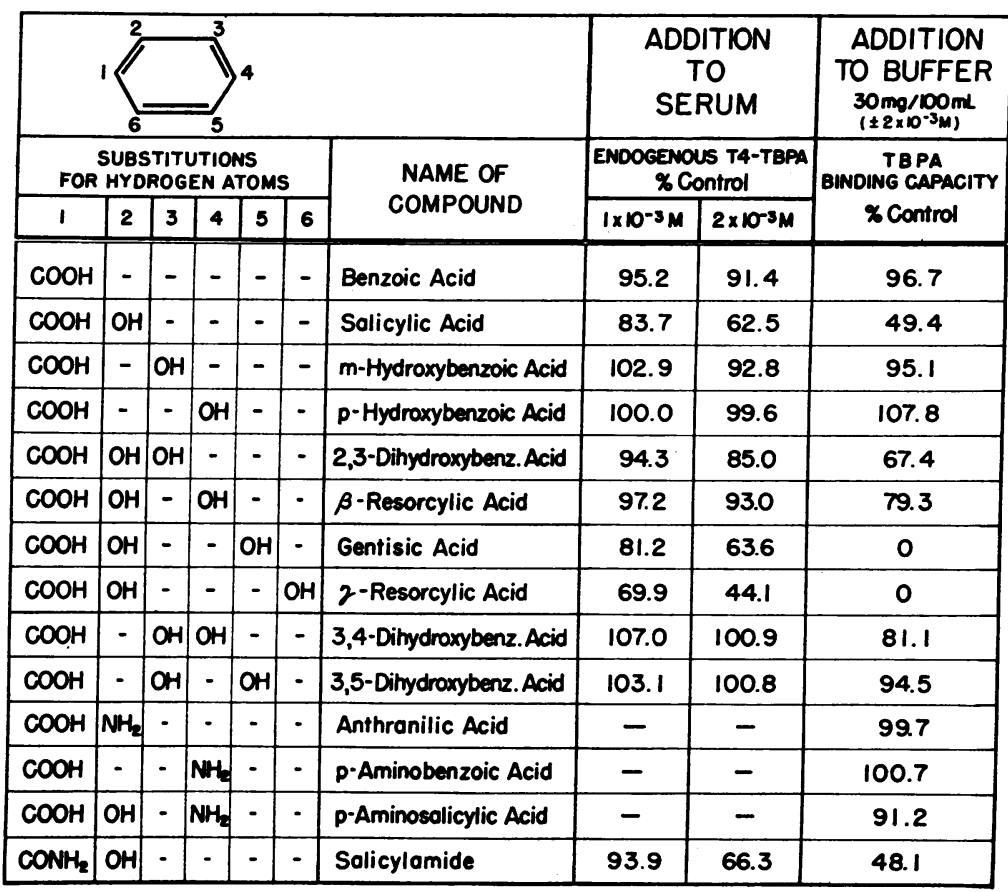

Fig. 1. The structural formulae and COMMON NAMES OF BENZOIC ACID AND SEVERAL OF ITS DERIVATIVES AND THEIR EFFECT ON THE THYROXINE ( $T_{4}$ )-BINDING ACTIVITY OF PREALBUMIN (TBPA) AS ASSESSED BY FILTER PAPER ELECTROPHORESIS IN TRIS-MALEATE BUFFER, PH 8.6. Under "addition to serum," values represent the proportion of a small tracer concentration of labeled $T_{4}$ bound to TBPA in the presence of inhibitor, expressed as a percentage of the comparable proportion in control specimens. Under "addition to buffer," values represent the mean of the micrograms of $T_{4}$ bound to TBPA at 386 and $450 \mu \mathrm{g}$ of $\mathrm{T}_{4}$ per $100 \mathrm{ml}$ of serum in the presence of inhibitor, expressed as a percentage of control values. Since inhibition couid be shown to be competitive, values in the presence of inhibitor are not, strictly speaking, binding capacities. At higher concentrations of $T_{4}$, additional binding of $T_{4}$ might occur, but dilution of labeled $T_{4}$ would prohibit accurate measurement. 
sumption was determined on multiple occasions during the control and experimental periods. PBI or BEI values reported represent the mean of at least three determinations during each period. The $\mathrm{T}_{4}$-binding activity of sera obtained during control and experimental periods was assessed by enriching such sera with tracer quantities of $\mathrm{I}^{231}$-labeled $\mathrm{T}_{4}$ and subjecting them to electrophoresis in filter paper in Tris-maleate buffer, as described above. Concentrations of the benzoic acid derivatives in serum were determined by a spectrophotometric technique (27). Statistical analyses were performed according to methods described by Snedecor (28).

\section{Results}

$T_{4}$ binding in serum. Figure 1 summarizes the effects of benzoic acid and 13 of its derivatives, including salicylate, on the binding of $T_{4}$ by TBPA as assessed by electrophoresis of serum in filter paper at $\mathrm{pH}$ 8.6. Certain of the derivatives, such as gamma-resorcylic acid and gentisic acid, when added either directly to the serum or to the buffer, were found to be potent inhibitors of $\mathrm{T}_{4}$ binding by TBPA but did not, even at the
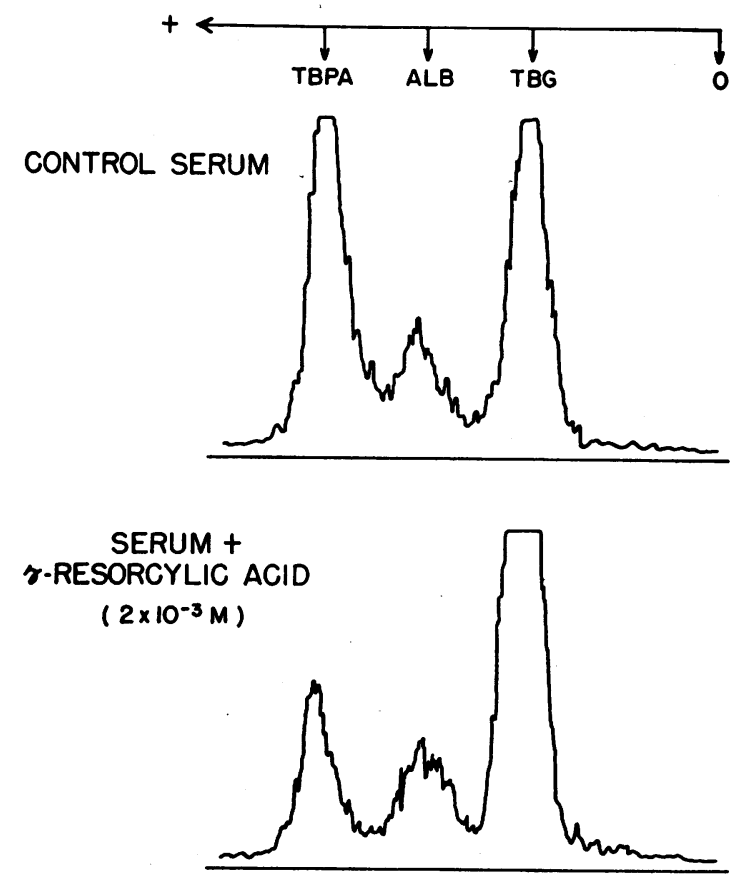

Fig. 2. The EFFeCt OF ADDING $\gamma$-RESORCYLIC ACID to NORMAL SERUM ON THE BINDING OF A SMALL TRACER CONCENTRATION OF I ${ }^{131}$-LABELED THYROXINE, AS ASSESSED BY FILTER PAPER ELECTROPHORESIS IN TRIS-MALEATE BUFFER, $\mathrm{PH}$ 8.6. $\mathrm{TBPA}=\mathrm{T}_{4}$-binding prealbumin; $\mathrm{ALB}=$ albumin; $T B G=T_{4}$-binding globulin.
TABLE I

The effect of adding thyroxine $\left(T_{4}\right)$ to serum on the inhibition of thyroxine-binding by TBPA induced by gamma-resorcylic acid as assessed by filter paper electrophoresis*

\begin{tabular}{ccc}
\hline & \multicolumn{2}{c}{$\begin{array}{c}T_{4} \text { bound to TBPA } \\
\text { in serum }\end{array}$} \\
\cline { 2 - 3 } $\begin{array}{c}T_{4} \text { con- } \\
\text { centration }\end{array}$ & Control & $\begin{array}{c}\text { Gamma- } \\
\text { resorcylic } \\
\text { acidt }\end{array}$ \\
\hline$\mu g / 100 \mathrm{ml}$ & $\%$ & $\%$ \\
12.6 & 27.7 & 10.3 \\
137.6 & 44.9 & 29.3 \\
162.6 & 40.2 & 30.8 \\
398.6 & 19.3 & 18.8 \\
462.6 & 16.3 & 16.2 \\
\hline
\end{tabular}

* $\mathrm{T}_{4}$ refers to the levorotatory isomer of thyroxine. TBPA $=T_{4}$-binding prealbumin.

† At $3 \times 10^{-3} \mathrm{M}$.

high concentrations employed, inhibit binding of $\mathrm{T}_{4}$ by albumin or TBG.

Figure 2 demonstrates a typical result obtained when the binding of an essentially endogenous concentration of $T_{4}$ in normal serum was compared with that in the same serum enriched with gamma-resorcylic acid. In the control serum, $\mathrm{T}_{4}$ was normally distributed among TBPA, TBG, and, to a slight extent, albumin. In the serum containing gamma-resorcylic acid, in contrast, $\mathrm{T}_{4}$ binding by TBPA was inhibited, and the $T_{4}$ displaced from TBPA was associated almost completely with TBG.

Table I demonstrates that the inhibitory activity of these derivatives, when added directly to serum, was progressively decreased and ultimately abolished by increasing concentrations of $T_{4}$. Therefore, the effect of the derivatives on the $\mathrm{T}_{4^{-}}$ binding capacity of TBPA was assessed by adding them to the electrophoretic buffer. As shown in Figure 3, high concentrations of $T_{4}$ in the serum, when subjected to electrophoresis in Trismaleate buffer, were bound predominantly to albumin and TBPA. The same serum was subjected to concurrent electrophoresis in buffer enriched with gamma-resorcylic acid. Here, $\mathrm{T}_{4}$ binding by TBPA was completely suppressed, and the $T_{4}$ displaced from TBPA was bound almost entirely to albumin. In addition, the proportion of $\mathrm{T}_{4}$ migrating to the inter-alpha globulin zone increased. Owing to the presence of a greater quantity of the derivative, the inhibition of $T_{4}$ binding by TBPA was greater when the derivatives were added to the electrophoretic buffer 


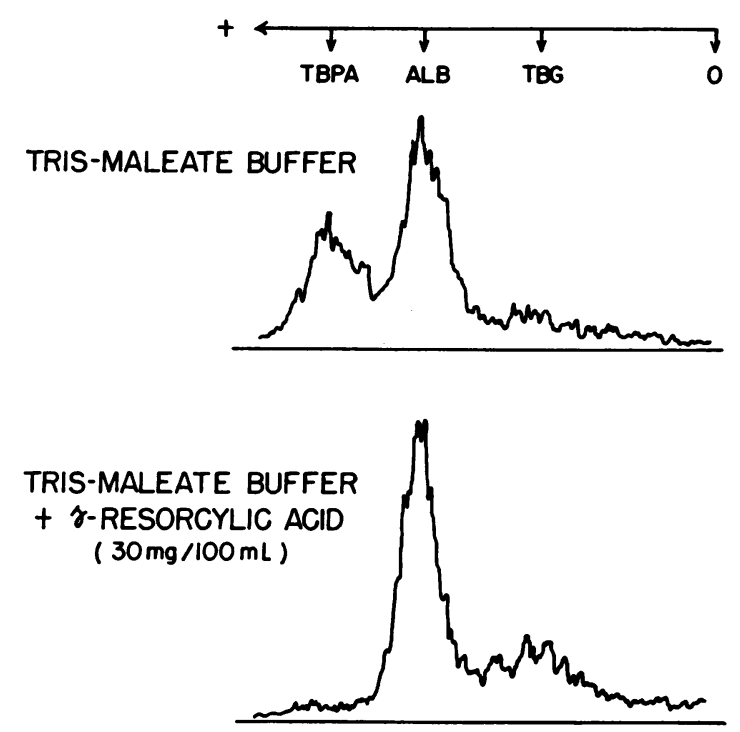

FIG. 3. THE EFFECT OF ADDING $\gamma$-RESORCYLIC ACID TO TRIS-MALEATE BUfFER, PH 8.6, ON THE THYROXINE-BINDING CAPACITY OF TBPA IN SERUM, AS ASSESSED BY FILTER PAPER ELECTROPHORESIS.

than when they were added directly to the serum. The results obtained by the two methods, however, were qualitatively similar.

In the agar gel electrophoretic system at $\mathrm{pH}$ $7.4, \mathrm{~T}_{4}$ in control serum was normally distributed among TBPA, TBG, and, to a slight extent, albumin. In the same serum to which either gamma-resorcylic acid or gentisic acid had been added, $\mathrm{T}_{4}$ binding by TBPA was inhibited (Figure 4). Direct counting of the radioactive zones confirmed these changes and indicated that the $\mathrm{T}_{4}$ was displaced almost quantitatively from TBPA onto TBG. No evidence was obtained that either of these derivatives interfered with $\mathrm{T}_{4}$ binding by albumin or TBG.

As shown in Table II, gamma-resorcylic acid

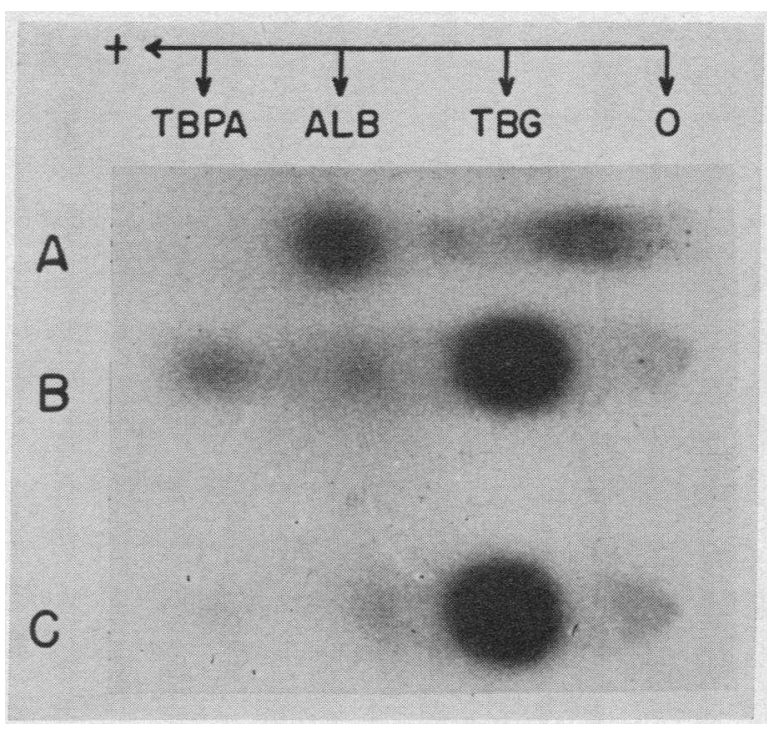

Fig. 4. RADIOAUTOGRAPH SHOWING THE EFFECT OF ADDING $\gamma$-RESORCYLIC ACID TO SERUM ON THE BINDING OF A SMALL TRACER CONCENTRATION OF I ${ }^{131}$-LABELED TH YROXINE, AS ASSESSED BY AGAR GEL ELECTROPHORESIS AT PH 7.4. A) Human serum albumin (1 g per $100 \mathrm{ml})$; B) control serum; C) serum enriched with $\gamma$-resorcylic acid $\left(3 \times 10^{-3} \mathrm{M}\right)$.

caused a highly significant increase in the rate of dialysis of labeled $\mathrm{T}_{4}$ from normal serum buffered at $\mathrm{pH}$ 7.4. In contrast, para-hydroxybenzoic acid, which did not inhibit $\mathrm{T}_{4}$ binding by TBPA as assessed by electrophoresis, had no effect in the dialysis system.

$T_{4}$ metabolism in vivo. Table III summarizes the results of the ten experiments carried out in the eight patients. Figure 5 presents a typical curve for the disappearance of the labeled $T_{4}$ from serum. In all the patients, an increase in the fractional rate of $\mathrm{T}_{4}$ turnover $(\mathrm{k})$ was observed during the administration of gentisic acid, gamma-resorcylic acid, or salicylamide. For the

TABLE II

The effects of gamma-resorcylic acid and para-hydroxybenzoic acid on the rate of dialysis of $I^{131-l a b e l e d}$ thyroxine $\left(T_{4}\right)$ from whole human serum at $\mathrm{pH} 7.4^{*}$

\begin{tabular}{lccc}
\hline \hline & Rate of dialysis of PBI I11 & p valuet & $\begin{array}{c}\text { T/ bound } \\
\text { to TBPA }\end{array}$ \\
\hline & $\%$ added $T / /$ hour & & $\%$ \\
Control & $0.0078 \pm 0.0008$ & & 27.7 \\
Para-hydroxybenzoic acid & $0.0078 \pm 0.0006$ & $>0.9$ & 30.9 \\
Gamma-resorcylic acid & $0.0230 \pm 0.0013$ & $<0.001$ & 10.3
\end{tabular}

* Derivatives in serum employed at a $3 \times 10^{-3} \mathrm{M}$ concentration. Values shown represent mean $\pm \mathrm{SE}$ of five observations. $\mathrm{PBI}=$ protein-bound iodine.

$\dagger p$ values represent the probability of a chance difference from those obtained in control specimens. 
KENNETH A. WOEBER AND SIDNEY H. INGBAR

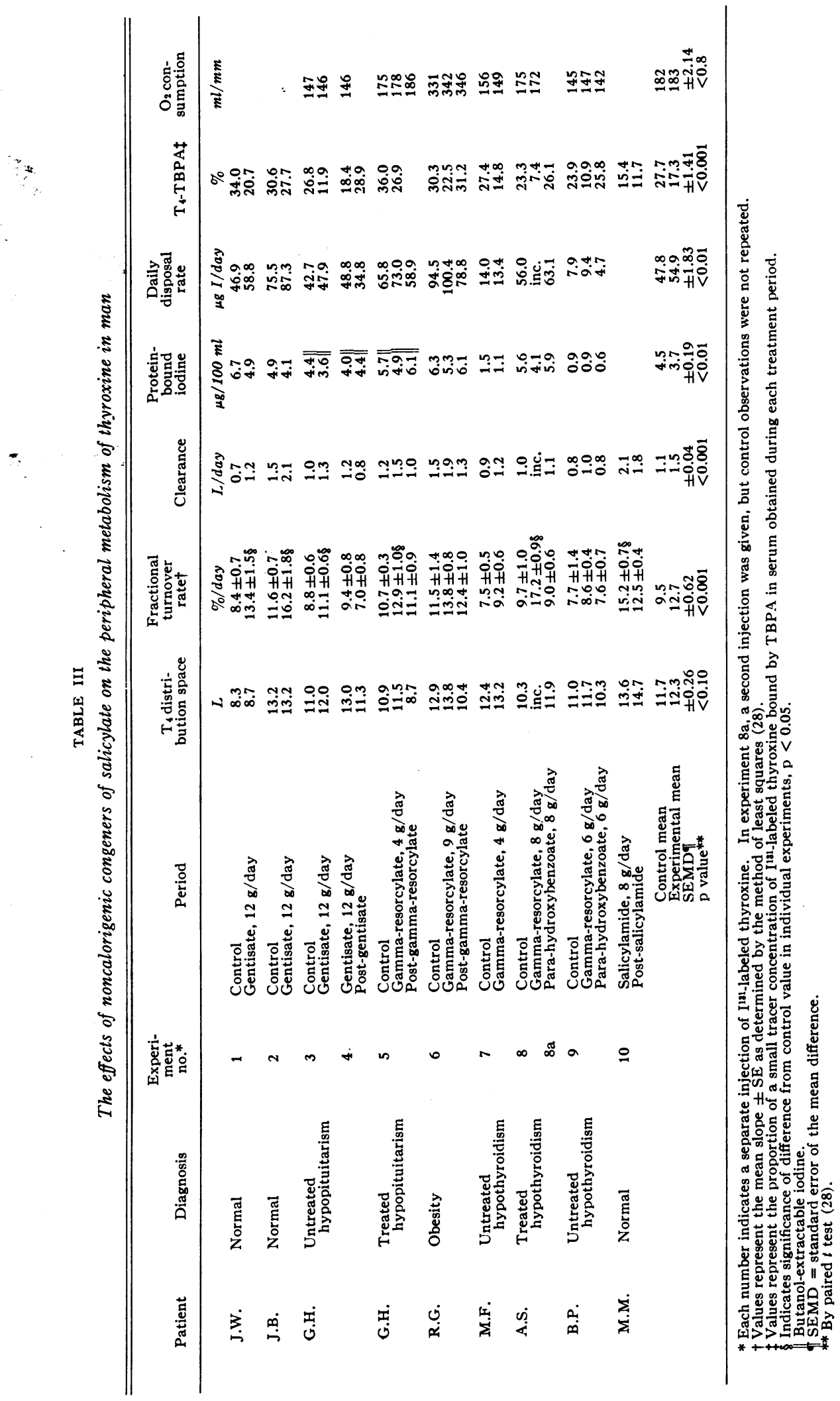




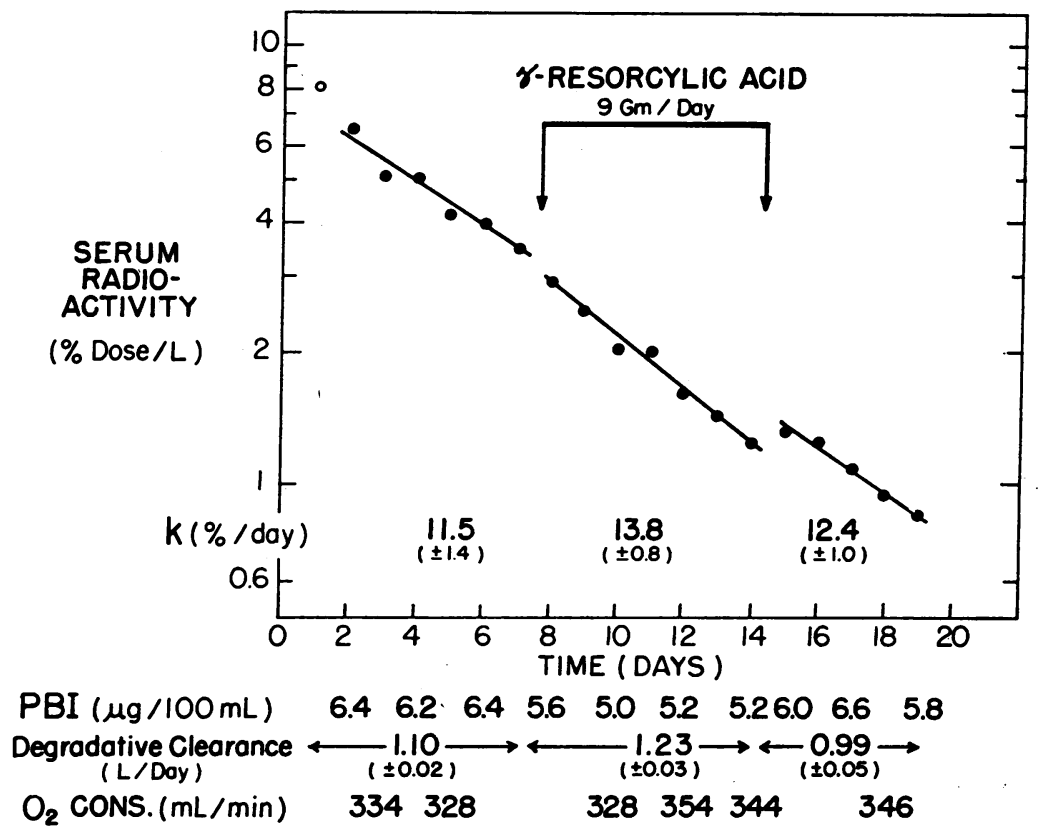

Fig. 5. THE EFFECT OF ADMINISTRATION OF $\gamma$-RESORCYLIC ACID TO PATIENT R.G. ON THE PERIPHERAL TURNOVER AND CONCENTRATION OF THYROXINE AND oN OXYGEN consumption. PBI = protein-bound iodine; $\mathrm{k}=$ rate of $\mathrm{T}_{4}$ turnover.

entire group of experiments, the average increase was $34 \%$, and this change was highly significant statistically $(p<0.001)$. Values for $k$ obtained in individual experiments were significantly altered by the derivative in six of ten instances. Except in the case of patient B.P., who had untreated hypothyroidism and whose PBI was abnormally low, a decrease in the PBI occurred in all experiments, and this change was highly significant statistically for the group as a whole ( $p$ $<0.01)$. Values for both the fractional turnover rate and PBI returned toward control values when the derivatives were discontinued.
As shown in Figure 5, a decrease of the radioactivity in serum occurred during the first 24 hours after the derivative was begun, whereas an increase occurred when the derivative was discontinued. In one experiment (Patient A.S.), the concentration of the radioactivity in serum fell sharply during the first 48 hours of the experimental period and then for 3 days showed little change, after which an increase in the exponential rate of disappearance occurred. Although the TDS was increased during the administration of the derivative, the long time interval required to attain a steady state precluded calculation of the

TABLE IV

The effect of gamma-resorcylic acid on the peripheral metabolism of thyroxine $\left(T_{4}\right)$ in man

\begin{tabular}{|c|c|c|c|c|}
\hline Patient & Period & $\begin{array}{l}\text { Total } T_{4} \\
\text { clearance }\end{array}$ & $\begin{array}{c}\text { Degradative } \\
\text { clearance }\end{array}$ & $\begin{array}{l}\text { Excretory } \\
\text { clearance }\end{array}$ \\
\hline R.G. & $\begin{array}{l}\text { Control } \\
\text { Gamma-resorcylate, } 9 \text { g/day } \\
\text { Post-gamma-resorcylate }\end{array}$ & $\begin{array}{l}L / \text { day } \\
1.49 \\
1.91 \\
1.29\end{array}$ & $\begin{array}{l}L / \text { day } \\
1.10 \pm 0.02 \\
1.23 \pm 0.03^{*} \\
0.99 \pm 0.05\end{array}$ & $\begin{array}{l}L / d a y \\
0.39 \\
0.68 \\
0.30\end{array}$ \\
\hline B.P. & $\begin{array}{l}\text { Control } \\
\text { Gamma-resorcylate, } 6 \mathrm{~g} / \mathrm{day} \\
\text { Para-hydroxybenzoate, } 6 \mathrm{~g} / \mathrm{day}\end{array}$ & $\begin{array}{l}0.84 \\
1.01 \\
0.79\end{array}$ & $\begin{array}{l}0.60 \pm 0.03 \\
0.72 \pm 0.03 \dagger \\
0.59 \pm 0.03\end{array}$ & $\begin{array}{l}0.24 \\
0.29 \\
0.20\end{array}$ \\
\hline
\end{tabular}

* Indicates significance of difference from both control and post-gamma-resorcylate values, $\mathrm{p}<0.01$.

$\dagger$ Indicates significance of difference from both control and para-hydroxybenzoate values, $\mathrm{p}<0.02$. 
TDS by the method described. In seven of the remaining nine experiments, calculated values for the TDS increased during administration of the binding inhibitors.

As a result of the changes in hormonal turnover and distribution, the daily clearance of $\mathrm{T}_{4}$ increased in all patients. Despite the lowering of the PBI that occurred during administration of the derivative, the daily rate of hormonal disposal, representing the product of daily clearance of $\mathrm{T}_{4}$ and PBI, increased by an average of $15 \%$, and this change was significant $(p<0.01)$ for the group as a whole.

In one patient (A.S.), no change in the kinetics of peripheral $\mathrm{T}_{4}$ metabolism was induced by the administration of para-hydroxybenzoic acid. In one other patient (B.P.), para-hydroxybenzoic acid failed to prevent the fractional turnover rate and PBI from returning toward control values after gamma-resorcylic acid had been withdrawn.

In the two patients (R.G. and B.P.) in whom such measurements were made, the degradative clearance of labeled $T_{4}$ increased significantly during the administration of gamma-resorcylic acid (Table IV). This value returned toward
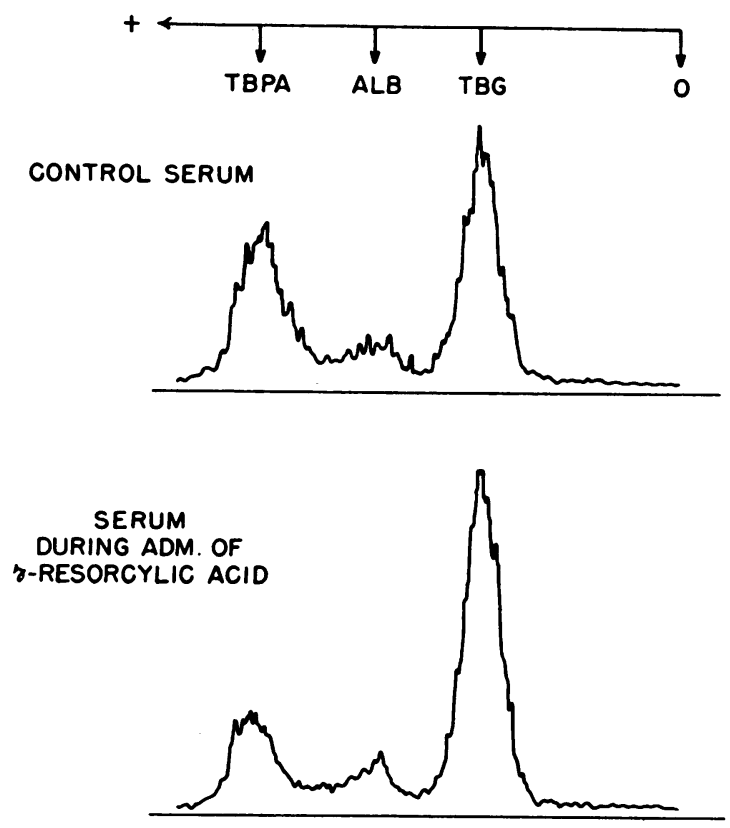

Fig. 6. Changes in THE BINDING OF A SMALl tRACER CONCENTRATION OF I31-LABELED THYROXINE IN SERUM DURING THE ADMINISTRATION TO PATIENT R.G. OF $\gamma$-RESORCYLIC ACID.
TABLE V

The effect of gentisic and gamma-resorcylic acids on the deiodination of $I^{131}$-labeled thyroxine by slices of rat kidney cortex*

\begin{tabular}{lcc}
\hline \hline \multicolumn{1}{c}{ Compound } & Concentration & $\begin{array}{c}\% \\
\text { of } \\
\text { deiontrol } \\
\text { deination }\end{array}$ \\
\hline Gentisic acid & $M$ & $\%$ \\
& $1 \times 10^{-3}$ & 22.4 \\
Gamma-resorcylic acid & $2 \times 10^{-4}$ & 77.4 \\
& $1 \times 10^{-5}$ & 86.2 \\
& $1 \times 10^{-3}$ & 63.4 \\
& $2 \times 10^{-4}$ & 96.0 \\
& $1 \times 10^{-5}$ & 101.0
\end{tabular}

* Values represent the proportion of thyroxine deiodinated, expressed as a percentage of the comparable value in the absence of derivative.

the control level when gamma-resorcylic acid was either stopped or replaced by para-hydroxybenzoic acid in a comparable dose.

As shown in Figure 6, serum obtained during administration of the derivative displayed a specific inhibition of $T_{4}$ binding by TBPA when subjected to electrophoresis in Tris-maleate buffer. This change in binding was comparable to that seen when the same derivative was added directly to serum in vitro. No change in the binding of $\mathrm{T}_{4}$ was seen in serum obtained during the administration of para-hydroxybenzoic acid.

In no instance did basal oxygen consumption change appreciably during the administration of the binding inhibitors.

$T_{4}$ degradation in vitro. Over a hundredfold range of concentration, encompassing those concentrations achieved in vivo, gamma-resorcylic acid and gentisic acid either inhibited or failed to influence the deiodination of $T_{4}$ by slices of rat kidney cortex. No stimulation of deiodination was evident (Table V).

\section{Discussion}

Increasing evidence indicates that a significant proportion of $\mathrm{T}_{4}$ in human serum is bound by TBPA $(5,9,10)$. To date, however, it has not been satisfactorily demonstrated that TBPA plays a role in regulating the peripheral metabolism of $\mathrm{T}_{4}$ in vivo. Because of accompanying abnormalities, such as hypermetabolism, which follows the administration of salicylate (17), or fever (12, 13 ), which occurs in a variety of systemic disorders, it has not been possible to ascribe the 
acceleration of $\mathrm{T}_{4}$ turnover occurring in these states to the inhibition of $\mathrm{T}_{4}$ binding by TBPA commonly seen in these conditions.

We found certain derivatives of benzoic acid to be specific inhibitors of $\mathrm{T}_{4}$ binding by TBPA, both at $\mathrm{pH} 8.6$ and 7.4. Indeed, two of the compounds, gentisic and gamma-resorcylic acids, proved to be more potent in this respect than salicylate itself. Both compounds have been used in the treatment of rheumatic fever and found to be free of serious side effects (29-32). In rats they are less toxic than salicylate (33). Since they also lack the calorigenic effects of salicylate $(21,22)$, they appeared to be ideal agents for use in assessing the effects on peripheral $\mathrm{T}_{4}$ metabolism of inhibiting the binding of $\mathrm{T}_{4}$ by TBPA. ${ }^{7}$ The studies that were therefore carried out have provided what is apparently the first strong evidence that TBPA plays a significant role in regulating the peripheral metabolism of $\mathrm{T}_{4}$ in man.

One concept of the function of the extracellular $\mathrm{T}_{\mathbf{4}}$-binding proteins, which appears to be true in the case of TBG, is that these proteins regulate the proportion of $T_{4}$ present in the free or unbound state and thereby limit the quantity of hormone available to the cells for metabolic action and degradation $(3,4)$. Within this concept, an inhibition of $T_{4}$ binding and the consequent increase in the proportion of free $T_{4}$ would permit a greater proportion of the total $\mathrm{T}_{4}$ to become affixed to the cell. This would be manifested in vivo by an expansion of the TDS and, if the fractional rate of degradation of cellular hormone were essentially unchanged, by an increase in the fractional turnover of hormone in the peripheral $\mathrm{T}_{4}$ pool. As a consequence, the total concentration of hormone in the peripheral pool would decrease until a new steady state is reached when total hormonal disposal once again equals hormonal supply. Presumably, this would occur when the total disposal of hormone has returned

\footnotetext{
7 In our studies, these compounds were well tolerated by the patients and did not change the state of hydration, as judged from serial measurements of the hematocrit. In three instances, mild dyspepsia occurred, but this was readily relieved by antacids. In the dosage employed (Table III), maximal serum concentrations of $12 \mathrm{mg}$ per $100 \mathrm{ml}$ were attained with gentisic acid, whereas gammaresorcylic acid was present in concentrations exceeding $20 \mathrm{mg}$ per $100 \mathrm{ml}$.
}

to normal values. If the function of TBPA is similar to that which has been ascribed to TBG, then these are the consequences that would be expected to follow the administration of gentisic acid or gamma-resorcylic acid. Such was indeed the case.

In the present studies, the administration of gentisic acid or gamma-resorcylic acid was accompanied by an abrupt lowering in the concentration of labeled $T_{4}$ in serum and by an increase in the subsequent slope of the exponential disappearance curve. As judged by conventional analysis, these changes resulted from an increase in the total volume of distribution and the fractional rate of turnover of the peripheral $T_{4}$ pool. These functions returned toward control values when the binding inhibitors were withdrawn.

Although there is evidence that the binding of $\mathrm{T}_{4}$ limits the rapidity with which $\mathrm{T}_{4}$ is removed from the plasma by excretory processes (34), an enhancement in the excretion of $\mathrm{T}_{4}$ could not alone have accounted for the observed effects of the binding inhibitors, since in the two patients in whom it was measured, degradative clearance increased significantly during inhibition of $T_{4}$ binding by TBPA. Nevertheless, since the increase in degradative clearance during this time was less than the increase in total $\mathrm{T}_{4}$ clearance, obviously the inhibitor also accelerated the excretory disposal of $\mathrm{T}_{\mathbf{4}}$.

An additional predicted consequence of diminished binding of $\mathrm{T}_{4}$ would be a decrease in the PBI. We consistently observed such a decrease during the administration of the binding inhibitors, although we rarely saw values in the subnormal range. This change, however, could possibly have resulted from other mechanisms. Wolff and Austen have shown that the noncalorigenic congeners of salicylate, as well as salicylate itself, slow the rate of release of thyroidal $\mathrm{I}^{131}$ in rats (35); these authors have also demonstrated a comparable effect of salicylate in normal humans (35). A decreased rate of secretion of hormone could, in itself, account for a lowering of the PBI; however, several observations indicate that this was not the major factor in our studies. First, a decrease in the PBI during the administration of gamma-resorcylate, comparable to that observed in the normal patients, was seen in the patient with treated hypothyroidism. Second, in 
all patients, a nearly maximal decline in PBI was observed within the first 24 hours of administration of the inhibitor. This decrease was greatly in excess of that which would have been expected from even a complete inhibition of $T_{4}$ secretion. Finally, in studies in patients with diffuse toxic goiter, not herein reported, gentisic acid and gamma-resorcylic acid failed to slow the disappearance of $\mathrm{I}^{131}$ from the thyroid but, nevertheless, caused a significant decline in the PBI (36). The small, although significant, decrease in the PBI that the derivatives induced would be consistent with previous conclusions that, although $\mathrm{T}_{4}$ binding by TBPA may have important effects on hormonal turnover, the proportion of hormone in the serum bound by TBPA is relatively small (5).

Contrary to expectations, in most patients the daily rate of hormonal disposal was greater than the control rate during administration of the binding inhibitors. Insufficient data are available, however, to determine whether, with more prolonged administration of the inhibitors, PBI would have continued to decline and hormonal disposal would eventually have returned toward control values.

In accord with previous studies in rats $(21,22)$, the present experiments indicate that gammaresorcylic and gentisic acids do not induce hypermetabolism in man. Since hormonal disposal and degradative clearance were increased by the inhibitors of TBPA, the lack of calorigenic action may indicate that the increment of cellular hormone induced by the binding inhibitors was not available for the induction of metabolic action. On the other hand, the normal individual can ingest relatively large quantities of thyroid hormone without developing hypermetabolism, and this tolerance to the hormone may explain the normal metabolic rates maintained by the patients in the present study (37).

Finally, within the limitations of extrapolating findings in animal tissues to the human situation, no evidence could be obtained that these agents directly stimulate cellular mechanisms for the deiodination of $T_{4}$. In view of all the foregoing evidence, the effects of these agents on the metabolism of $T_{4}$ in man can be ascribed only to their effect on the binding of $\mathrm{T}_{4}$ by TBPA. The data would therefore suggest that TBPA plays an im- portant role in regulating the peripheral metabolism of $\mathrm{T}_{4}$ in man.

\section{Summary}

Several noncalorigenic congeners of salicylate have been found to inhibit thyroxine binding by human serum prealbumin, both at $\mathrm{pH} 8.6$ and 7.4 , without interfering with the binding of thyroxine by other thyroxine-binding proteins. In man, these binding inhibitors lowered the proteinbound iodine in serum and increased both the fractional and total daily turnovers of thyroxine. The changes in thyroxine metabolism occurred without hypermetabolism or systemic side effects and did not depend upon a direct stimulation of the cellular mechanisms of thyroxine degradation. Thus, the effect of these agents on thyroxine metabolism could be ascribed only to their effect on the binding of thyroxine by prealbumin. The data therefore provide strong evidence that thyroxine-binding prealbumin plays an important role in regulating the metabolism of thyroxine in man.

\section{Acknowledgment}

The authors are indebted to Miss Carol Beach for technical assistance.

\section{Appendix}

The present studies provide some information concerning the binding of small molecules by TBPA. The inhibitory potency of the derivatives of benzoic acid could be correlated with the nature and steric arrangement of substituents on the benzene ring. A hydroxyl group on carbon 2, ortho to the carboxyl group, was necessary for significant inhibitory activity. This was enhanced by additional hydroxyl substitution at carbons 5 or 6, gentisic (2,5-dihydroxybenzoic) acid and gammaresorcy'ic (2, 6-dihydroxybenzoic) acid being the most potent inhibitors found. The inhibitory activity of compounds possessing an ortho-hydroxyl group was reduced by hydroxyl substitutions at carbons 3 or 4 or by amino substitutions.

The presence of an electronegative hydroxyl group ortho to the carboxyl group affects the molecule of benzoic acid in a number of ways. First, through its inductive effect, an electronegative substituent favors ionization of the carboxyl group, and this effect is greatest when the substituent is nearest or ortho to the point of attachment of the carboxyl group (38). Second, hydrogen-bond formation between the ortho-hydroxyl group and the ionized carboxyl group hinders return of the proton, thus increasing the degree of ionization of the 
carboxyl group (39). Third, by invoking a charge separation in the anion, ortho- or para-substituents allow the phenyl group to participate in the resonance (38). Owing to the greater number of forms contributing to the resonance hybrid, resonance stabilization of the anion is increased. All three effects, therefore, tend to increase the acidic dissociation constants of the ortho-hydroxyl substituted derivatives over that of the parent compound. Thus, gamma-resorcylic acid, which has two ortho-hydroxyl groups, has a dissociation constant 50 times greater than that of salicylic acid and 800 times greater than that of benzoic acid (39). Thus, although it is not clear how this relationship is manifested, there appears to be a definite inverse correlation between the $\mathrm{pK}$ of the carboxyl group and the inhibitory potency of the compounds tested. Indeed, only the ortho-hydroxyl substituted derivatives were found to be competitive inhibitors of $\mathrm{T}_{4}$ binding by TBPA. The high concentrations of these derivatives that were necessary to inhibit $T_{4}$ binding by TBPA and the reversal of inhibition that was achieved by relatively small concentrations of added $T_{4}$ indicate, however, that their binding constants are, by several orders of magnitude, lower than that of $T_{4}$.

\section{References}

1. Gordon, A. H., J. Gross, D. O'Connor, and R. PittRivers. Nature of the circulating thyroid hormone-plasma protein complex. Nature (Lond.) 1952, 169, 19.

2. Ingbar, S. H. Pre-albumin : a thyroxine-binding protein of human plasma. Endocrinology 1958, 63, 256.

3. Robbins, J., and J. E. Rall. Proteins associated with the thyroid hormones. Physiol. Rev. 1960, $40,415$.

4. Ingbar, S. H., and N. Freinkel. Regulation of the peripheral metabolism of the thyroid hormones in Recent Progress in Hormone Research. New York, Academic Press, 1960, p. 353.

5. Ingbar, S. H. Observations concerning the binding of thyroid hormones by human serum prealbumin. J. clin. Invest. 1963, 42, 143.

6. Federman, D. D., J. Robbins, and J. E. Rall. Effects of methyltestosterone on thyroid function, thyroid metabolism, and thyroxine-binding protein. J. clin. Invest. 1958, 37, 1024.

7. Dowling, J. T., N. Freinkel, and S. H. Ingbar. The effect of estrogens upon the peripheral metabolism of thyroxine. J. clin. Invest. 1960, 39, 1119.

8. Ingbar, S. H. Clinical and physiological observations in a patient with an idiopathic decrease in the thyroxine-binding globulin of plasma. J. clin. Invest. 1961, 40, 2053.

9. Hollander, C. S., V. V. Odak, T. E. Prout, and S. P. Asper, Jr. An evaluation of the role of prealbumin in the binding of thyroxine. J. clin. Endocr. 1962, 22, 617.

10. Oppenheimer, J. H., R. Squef, M. I. Surks, and $H$. Hauer. Binding of thyroxine by serum pro- teins evaluated by equilibrium dialysis and electrophoretic techniques. Alterations in non-thyroidal illness. J. clin. Invest. 1963, 24, 1769.

11. Richards, J. B., J. T. Dowling, and S. H. Ingbar. Alterations in the plasma transport of thyroxine in sick patients and their relation to the abnormality in Graves' disease (abstract). J. clin. Invest. 1959, 38, 1035.

12. Sterling, K., and R. B. Chodos. Radiothyroxine turnover studies in myxedema, thyrotoxicosis and hypermetabolism without endocrine disease. J. clin. Invest. 1956, 35, 806.

13. Braverman, L. E., and S. H. Ingbar. Unpublished observations.

14. Ingbar, S. H., and N. Freinkel. Studies of thyroid function and the peripheral metabolism of $\mathrm{I}^{131}$ labeled thyroxine in patients with treated Graves' disease. J. clin. Invest. 1958, 37, 1603.

15. Wolff, J., M. E. Standaert, and J. E. Rall. Thyroxine displacement from serum proteins and depression of serum protein-bound iodine by certain drugs. J. clin. Invest. 1961, 40, 1373.

16. Woeber, K. A., and S. H. Ingbar. Effect of salicylate on the binding of thyroxine by human serum proteins at $\mathrm{pH}$ 7.4. Endocrinology 1963, 73, 118.

17. Austen, F. K., M. E. Rubini, W. H. Meroney, and J. Wolff. Salicylates and thyroid function. I. Depression of thyroid function. J. clin. Invest. 1958, 37, 1131.

18. Castor, C. W., and W. Beierwaltes. Effect of 2,4-dinitrophenol on thyroid function in man. J. clin. Endocr. 1956, 16, 1026.

19. Brody, T. M. Action of sodium salicylate and related compounds on tissue metabolism in vitro. $\mathrm{J}$. Pharmacol. exp. Ther. 1956, 117, 39.

20. Loomis, W. F., and F. Lipmann. Reversible inhibition of the coupling between phosphorylation and oxidation. J. biol. Chem. 1948, 173, 807.

21. Meade, B. W. Effect of certain hydroxybenzoic acids on the oxygen consumption of Wistar rats. Ann. rheum. Dis. 1954, 13, 60.

22. Andrews, M. M. The relative potencies of some substituted salicylic acids as metabolic stimulants in the intact rat. Brit. J. Pharmacol. 1958, 13, 419.

23. Taurog, A. Deiodination of $\left.{ }^{(131} \mathrm{I}\right)$ thyroxine on filter paper. Biochim. biophys. Acta (Amst.) 1962, 60, 197.

24. Richards, J. B., and S. H. Ingbar. The effects of propylthiouracil and perchlorate on the biogenesis of thyroid hormone. Endocrinology 1959, 65, 198.

25. Ingbar, S. H., and N. Freinkel. Simultaneous estimation of rates of thyroxine degradation and thyroid hormone synthesis. J. clin. Invest. 1955, 34, 808 .

26. Benotti, J., and N. Benotti. Protein-bound iodine, total iodine, and butanol-extractable iodine by partial automation. Clin. Chem. 1963, 9, 408. 
27. Gerald, P. S., and B. M. Kagan. A method for the determination of gentisic acid in serum. J. biol. Chem. 1951, 189, 467.

28. Snedecor, G. W. Statistical Methods Applied to Experiments in Agriculture and Biology, 5th ed. Ames, Iowa, The Iowa State University Press, 1956.

29. Meyer, K., and C. Ragan. The antirheumatic effect of sodium gentisate. Science 1948, 108, 281.

30. Shaefer, L. E., I. A. Rashkoff, and R. S. Megibow. Sodium gentisate in the treatment of acute rheumatic fever. Circulation 1950, 2, 265.

31. Clarke, N. E., R. E. Mosher, and C. N. Clarke. Phenolic compounds in the treatment of rheumatic fever. I. A study of gentisic acid derivatives. Circulation 1953, 7, 247.

32. Clarke, N. E., C. N. Clarke, and R. E. Mosher. Phenolic compounds in chemotherapy of rhel:matic fever. Amer. J. med. Sci. 1958, 235, 7.
33. Goodman, L. S., and A. Gilman. The Pharmacological Basis of Therapeutics, 2nd ed. New York, Macmillan, 1955, p. 299.

34. Myant, N. B. Relation between the biliary clearance rate of thyroxine and the binding of thyroxine by the serum proteins. J. Physiol. (Lond.) 1957, $135,426$.

35. Wolff, J., and F. K. Austen. Salicylates and thyroid function. II. The effect on the thyroid-pituitary interrelation. J. clin. Invest. 1958, 37, 1144.

36. Woeber, K. A., and S. H. Ingbar. Unpublished observations.

37. Riggs, D. S., E. B. Man, and A. W. Winkler. Serum iodine of euthyroid subjects treated with desiccated thyroid. J. clin. Invest. 1945, 24, 722.

38. Herbst, R. M. Tetrazoles as carboxylic acid analogs in Essays in Biochemistry, S. Graff, Ed. New York, John Wiley and Sons, 1956, p. 141.

39. Baker, W. Abnormal strength of 2,6-dihydroxybenzoic acids. Nature (Lond.) 1936, 137, 236. 